\title{
FUNNY OR AGGRESSIVE? FAILED HUMOUR IN INTERNET COMMENTS
}

\author{
Liisi Laineste
}

\begin{abstract}
Jokes, ethnic slurs and parodies often occur in Internet comments, as the general feeling of anonymity allows for and even favours balancing on the verge of the acceptable and the unacceptable. Thus, a humorously intended comment can be perceived as aggressive by other Internet users. This possibility is further enhanced by the fact that the electronic media in general and computer mediated communication (CMC) in particular lacks non-verbal conversational cues that would signal the intentions of the communicator with greater, though not absolute, accuracy. The interrelations between online humour and aggression have so far escaped the attention of researchers, although scholarly discussions concerning these two phenomena in face-to-face interaction have been frequent.

This paper analyses comment sequences in the Delfi news portal (www.delfi. ee) from 2000 to 2007. Delfi is an Estonian online news website known for its liberal attitude towards commenting. The aim of the article is to describe the boundaries between humour and verbal aggressiveness and address the notion of failed humour through its occurrence in online communication. In addition to presenting the patterns of humorous and aggressive modalities in comment sequences, some cases in which humour changes into aggressiveness are analysed.
\end{abstract}

Keywords: Internet, computer mediated communication, humour, verbal aggression, failed humour

\section{INTRODUCTION}

Folkloristic account of humour has in recent decades become rather interdisciplinary as different aspects of humour are tied to such notions as xenophobia, group identity, creativity, subculturalisation, globalisation, etc. In order to embrace these phenomena, folklorists must include insights from other academic fields like sociology, ethnography, and psychology, to name just a few. As a considerable proportion of everyday interaction is moving to the Internet, all of the above-mentioned fields of study have made attempts to define the scope and methodologies of research on the Internet. 
A reliable analysis of contemporary humour should also include the Internet (both as a source and as a specific environment that shapes interaction), because it has become a primary present-day channel for humour. It is only logical that researchers should thus pay attention to humour as one of its main constituents. The entertaining function of the Internet is surpassing the practical, educational and other possible uses that the medium was initially designed to carry (Kirshenblatt-Gimblett 1996: 22; Blank 2009: 2). As a matter of fact, researchers of the Internet have stressed that more than simply being a medium, the Internet presents a specific cultural context. This means that internet culture should be studied in its own right (e.g. Hine 2005).

Particularly typical of computer mediated communication (CMC) is the enhanced ambiguity of statements. The social cues that would normally inform the recipient(s) about the intentions of the sender are missing and thus the meanings of a statement multiply, escaping the control of the author, and the message is received depending on the interpretation of the (global) audience. For this reason, a statement originally intended as humorous may be misinterpreted as an aggressive one, which is an example of failed humour (for two recent studies on failed humour in face-to-face communication, see Priego-Valverde 2009 and Bell 2009). In the following sections, an overview on aggression, humour and the interrelations of these two phenomena are given.

\section{CMC and aggression}

Aggression is an ever-present part of human society, although its expression differs across societies and cultures. In face-to-face interaction, its appearance is socially inhibited, and means of mass communication are censored for their aggressive content, but communication that occurs within the Internet is not often regulated for its aggressive content. Whereas the prominent features of Internet communication, namely that it allows for more interactivity and provides more detailed information compared to print media, radio and TV (Tsfati \& Weimann 2002), are positive in essence, the information the medium provides may at the same time be more shallow, dispersed and biased. Furthermore, what is most important in the context of this article: while earlier communication technologies may have contributed to shaping the message, they did not offer the same capacity for invoking as many fundamental social psychological processes that can be related to aggressiveness as the Internet does (Malamuth et al. 2009: 166). Research has shown that aggression is not dominant, but still an ever-present part of the Internet and CMC (Terezskiewicz 2012: 195-196; 
Laineste 2012: 180), ranging between 3 and 20 percent of its content (based on their analysis of internet comments and online social networks).

Online verbal aggression is generally known as flaming. Flaming initially referred to incessant talking or pointless chatter (for the history of the term, see Joinson 2007: 79). Since then, its scope has grown to include everything from impoliteness and swearing to excessive use of exclamations and superlatives (Kiesler et al. 1985); it can take the form of online communication in chat rooms and forums, but it can also be expressed through racist websites, stealing virtual identities, stalking, creating and spreading computer viruses, and much more. It has become a common term to designate any negative and antisocial verbal behaviour on computer networks - e.g. as a "form of personal verbal violence arising largely from the peculiar conditions of online writing" (Millard 1997: 145). Points that most researchers agree upon are that flaming is uninhibited, heated and emotional venting that occurs in computer networks. Anonymity and volatile identities are factors that contribute to engaging in online flaming.

In real life, people have an almost limitless array of behaviours besides words - they can use verbal or physical assault, or just give an angry look so that their body language supports their message. The online environment offers a much more limited set of options for expressing oneself. This has been described by a number of studies about computer-mediated communication (e.g. Hine 2005: 7) where the Internet has been referred to as an impoverished medium. A growing body of researches in the field of Internet studies assess the factors that enable the growing presence of aggressive statements online. So far, the main factor blamed for causing online aggression is the anonymity of the medium, but this is far from being the only one, as more recent studies show. Malamuth et al. (2009: 168) gives an overview of the reasons for online aggression, showing that there are a number of interactive factors that influence it. Instead of approaching the material from a single theory, the authors break the existing evidence down to three separate categories, and list the following three main incentives for flaming: (1) those creating the motivation to commit aggression, (2) those reducing internal and external inhibitions that might prevent acting out the desire to aggress, and (3) those providing the opportunity for the act to occur (ibid.). Thus, there is a plethora of mutually supportive reasons for online aggression.

Joinson (1998: 89-90) stresses that it is essential not to reduce the reasons for heightened aggression only to a single factor, i.e., the anonymity of the medium. The degree of personal engagement on different websites varies, as does the level of disinhibition that triggers flaming. In the present study, the website under examination is an anonymous discussion board where a clash 
of opinions is more inherent than, for example, in more personal online social networks, e.g. Facebook.

\section{CMC and humour}

Studies of Internet humour have until now disregarded the effect of the medium on the expression of humour; instead, the Internet is used as merely a convenient source of research material. At times, authors refer to particular characteristics of Internet humour as compared to face-to-face humorous communication (e.g. its rich context, cf. Oring 2003: 130, or faster dissemination, cf. Ellis 2001). As an exception to this rule, in one of the first articles on the subject, Nancy Baym (1995) described online humour in discussion groups, stressing its positive effect on group solidarity and its important role in identity formation.

Humour that occurs in comment sequences presents a different side of the phenomenon, as this kind of communication is more likely to create misunderstanding and failed humour than the more immediate and personalised interaction on discussion groups described by Baym. Humour in the Internet comment sequences rarely takes the form of a traditional punch-lined joke. A typical feature of CMC is citing previous texts, including other users' comments, both in ironic or factual manner. Intertextuality is thus continuously present in this medium: people use citations of known humorous texts (also parts / punch-lines of jokes, see also Shmelev \& Shmeleva 2009: 225) and winged words (Brzozowska 2009: 163). Full texts of jokes are left out because even though their form has considerably shortened (when compared to old folk jokes), they are still too long for the purposes of online communication. In addition to a variety of different forms of humour present in the online environment, the content may also vary from mild and playful jokes to teasing, satire or verbal attacks. In the latter, humour is often used as a disclaimer to hide the aggressive intentions of the joke-teller (for a thorough overview, see Oring 2003: 55-57). Although it has been hypothesised that due to reduced cues and subsequently more risks of misunderstanding, Internet users would be careful with using either humour or irony, research shows the opposite (e.g. Hancock 2004).

\section{Interrelations of humour and aggression}

In several studies, humour and aggression are often mentioned together or even defined through one another (Gruner 1997). Seemingly aggressive acts can appear as funny (for example, slapstick comedy is built on this implication), 
and, without context, much of what can be called humour may, under some circumstances, offend people.

Public discussions about the limits of humour and insults have often resulted in relatively incompatible points of view. What is an act of aggression to one party may be mere mirth for another, and tastes in humour can easily become a subject that one does not argue about. The reactions to a statement that was intended humorously or was expressed through humorous means may be unexpected to the initiator and can even result in actual physical violence (e.g. the Danish cartoon controversy in 2006, which exploded after a set of editorial cartoons about Muslims were published in the Danish newspaper JyllandsPosten; in subsequent reactions, protestors burned flags, organised consumer boycotts, attacked Danish embassies, etc). In this way, an argument of tastes can turn into a physical battle of defending one's right and ability to laugh (for discussion, see, e.g., Lewis 2008).

\section{Failed humour in CMC}

The notion of failed humour has entered the discipline of humour research only recently, and this is partly vested in the previously dominant assumption that by definition, humour should bring about a positive reaction (i.e., laughter). The numerous examples where a failed joke goes unnoticed, makes one shrug, become angry or insulted, were disregarded in the name of coherent analysis (for an overview, see also Hay 2001; Norrick 1993). By now it is evident that humour theory should also encompass failed humour in order to be able to define its object in the first place (Norrick \& Chiaro 2009: xiv).

Failed humour is very often met with anger or a biting remark. The alternating of humour and aggression is addressed in the analysis section of this article, because this can give insights into the ways how these two concepts are interrelated, answering the following research questions: (1) How do humorous and aggressive statements alternate? (2) Is failed humour in Internet comment sequences more likely to bring about aggressive and insulting statements?

Humour is essentially a non-bona-fide mode of communication (Raskin 1985), or in different terms, a communication characterised as paratelic activity (Apter 1982; Martin 2010). This means that in order for a joke to become potentially funny for the audience, they have to play along and accept the situation both on the level of the specific joke and on the level of its social context. In the case of some jokes, the audience must suspend the aversion towards its violent content (e.g. in the joke about brake marks in front of an animal who has been hit by a car, but no marks where an ethnic character has met a similar fate). The listen- 
ers have to accept that this is make-believe, a game that entails no real danger (in this example, damage neither to the animal nor to the ethnic character). If this condition is not fulfilled and a joke puzzles, irritates, is repulsive or evokes aggression, humour has failed. In face-to-face communication, audience expectations about humour (it should make one laugh, be entertaining) may have an effect on responses to failed humour (Bell 2009: 158). The initiator of humour has failed twice: has disrupted the conversation by telling a joke, and also has failed to entertain. Jennifer Hay's (2001: 67) model of humour apprehension points out that recognition, understanding and appreciation of humour must all be present in order for a joke to be successful. Each stage is a prerequisite for the next one. On the last level - that of humour appreciation - the existence of a shared cultural background and values becomes important, but a misunderstanding of the textual and contextual levels also leads to failure in humour appreciation. Trying to be humorous in CMC has different, yet quite understudied effects on conversation than attempted humour in face-to-face interaction and probably also follows different mechanisms for both initiating and reacting to humour. The expanding Internet environment draws together different people, whose reaction is affected by their group identity and aspects thereof (the existence and status of group leaders, identity construction and its stability; for a discussion about the same factors in face-to-face interaction, see Zillmann \& Cantor 1976: 100-101) as well as ethical convictions. We can propose that the appreciation of humour found on the Internet is simultaneously more and less probable, or, to put it differently, the diapason of possible reactions is wider. Positive humour appreciation is supported by the globalisation tendencies of the web, better knowledge of different cultures, and multiplicity of identities, whereas negative reactions to humour stem from the fragmentation of the media and its provocative quality backed up by anonymity and disinhibition.

\section{MATERIAL}

In order to answer the questions concerning the interaction of humour and aggression and the alternation of these two phenomena in anonymous comments, comment sequences on the least censored Estonian news website, Delfi (www. delfi.ee), were analysed. There are several reasons behind this choice: first of all, it attracts the widest variety of people (unlike, for example, a forum dedicated to one subject only); secondly, it allows for different opinions as well as their clash; and thirdly, it is one of the remaining safe havens of anonymity in the increasingly controlled medium. 
To characterise the targeted environment in a few words, Delfi is an everpopular news portal, designed to attract the highest number of readers, and the commentators are aware of the permissiveness this implies. It is characteristic that Delfi has been dubbed "the toilet wall" of Estonian Internet. After some polemics (and one person convicted for hate speech in 2005) there have been rearrangements in terms of reporting abuse - the editor can remove a comment if it is reported as abusive - but none of the comment threads in our dataset bore signs of this procedure. There were no 'white spots' that usually mark the place of a removed comment (today, comment editors do it more frequently). This permissiveness even extends to the journalists working for the portal. In an analysis of various online news portals in Estonia (Justiitsministeerium 2007), Delfi was reportedly the most provocative in wording news headlines. They are often formulated in a way that provokes aggressive reactions, or even better, a clash of opinions (Laineste 2012).

Based on the material of a previous study (see Justiitsministeerium 2007) that compared only aggressive statements in online comments, forums, blogs and social networking sites, the dataset compiled for this analysis consisted of 91 comment threads (from the section of domestic news) from the years 2000-2007, altogether 18,382 single comments. The particular time span was of interest because it included the year 2005 when discussion about free speech on the Internet was launched, as well as the politically quite controversial year 2007 (with regard to ethnic issues in Estonia), and also touched upon the years prior to this. To remove seasonal biases, we chose one week from each year: week 47 from 2000, week 5 from 2001, week 12 from 2002, week 19 from 2003, week 27 from 2004, week 33 from 2005, week 40 from 2006, and weeks 2 and 17 from 2007. Two threads from each day with the highest number of comments were included in the material.

The presence of humour was marked by explicit responses recognising funny performances, use of cues associated with humour, and the coder's assumptions of humour use. The presence of aggression was categorised (see also Tereszkiewic 2012: 187, using the model presented by Kayany 1998) through its verbal (personal attacks, venting, etc.) and non-verbal (capitalisation, emoticons, punctuation, etc.) expression. The categories of neither humour nor aggression were specified in more detail, although future research into the topic could benefit from differentiating, for example, between verbal and non-verbal aggressiveness. The category of aggressive statements was divided between general and targeted aggression, a decision which was further justified by the results. An additional category of neutral comments was used to cover the material as widely as possible. 


\section{RESULTS AND DISCUSSION}

\section{Alteration of humour and aggression in comment sequences on the Delfi news website}

Firstly, we will discuss the results concerning patterns of humour and aggression in comment sequences. The results of the analysis in the four identified categories (humour, general aggression, targeted aggression, and neutral) are presented on the graphs below. To visualise the alteration of these four different modes of comments, two threads - Reps: Külalistele vaeseid ei näidata (Reps: They don't show the poor to the visitors; Delfi, August 17, 2005) and Homoühendused taunivad Angeli kampaaniat (Gay societies are against the Angel campaign; Delfi, October 4, 2006) - were chosen, because they exemplify the overall trends in the material well. The graphs attempt to show the patterns - the density, coincidence, and alternation - of the four categories, which, in turn, give an insight into our first question, i.e., how humorous and aggressive statements alternate.

Figure 1 shows the incidence of humorous statements in a comment thread. Humour seems to present an 'opening act' for tackling the issue in the news text. Commentators try to reformulate the news from an unfamiliar angle, and find amusing elements or incongruence on the textual as well as semantic level. For example, one of them states: "She [Mailis Reps, the former Minister of Education] fell down from a tree and became minister straight away."

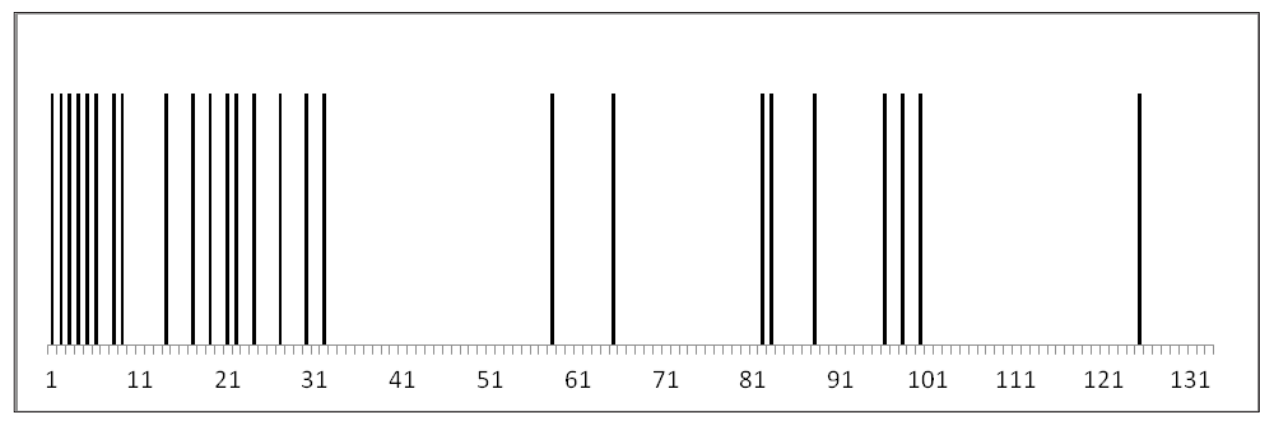

Figure 1. Humour in the news text "Reps: They don't show the poor to the visitors" (Delfi, August 17, 2005).

Aggression targeted at fellow commentators is more frequent towards the end of the thread (see Figure 2). People involved in the discussion, having used up 
all humorous as well as neutral statements, resort to insulting others whose comments annoy them, writing, for example: "to eip: I feel sorry for you, you victim of an abortion", or "to Keelemees: you were probably the brightest student of a special education facility[...]".

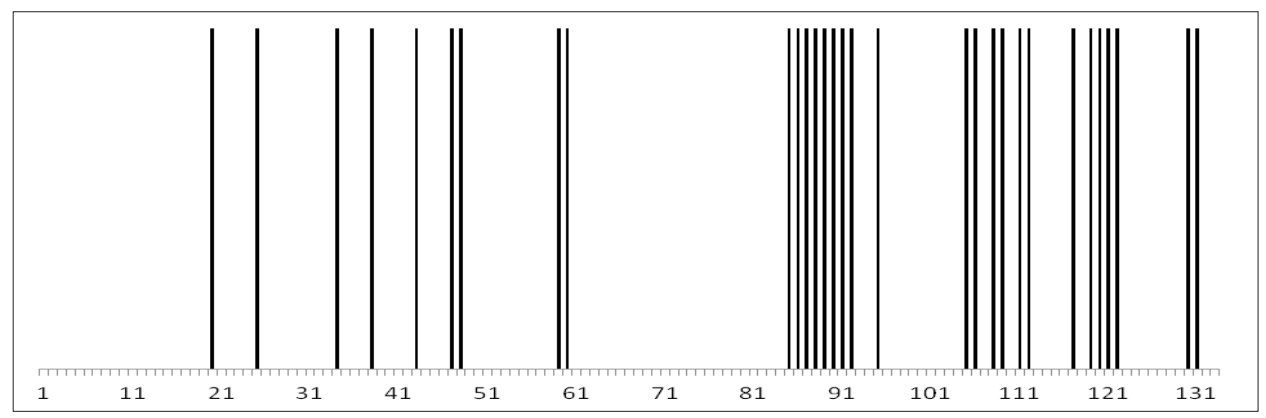

Figure 2. Targeted aggression in the news text "Reps: They don't show the poor to the visitors" (Delfi, August 17, 2005).

General aggression, on the other hand, is quite evenly present throughout the thread, with no particular high or low frequency segments (Figure 3). It is, as already mentioned, an ever-present background of online interaction; not dominant, but still visible. Statements that exemplify the graph are taken from the thread that deals with a campaign that the infamous gay nightclub Angel organised, giving out glow in the dark reflectors to raise awareness of homosexuality. As can be expected, the generally aggressive comments condemn the subculture of gays (e.g. "Fags should be put back in the closet. And force the door shut").

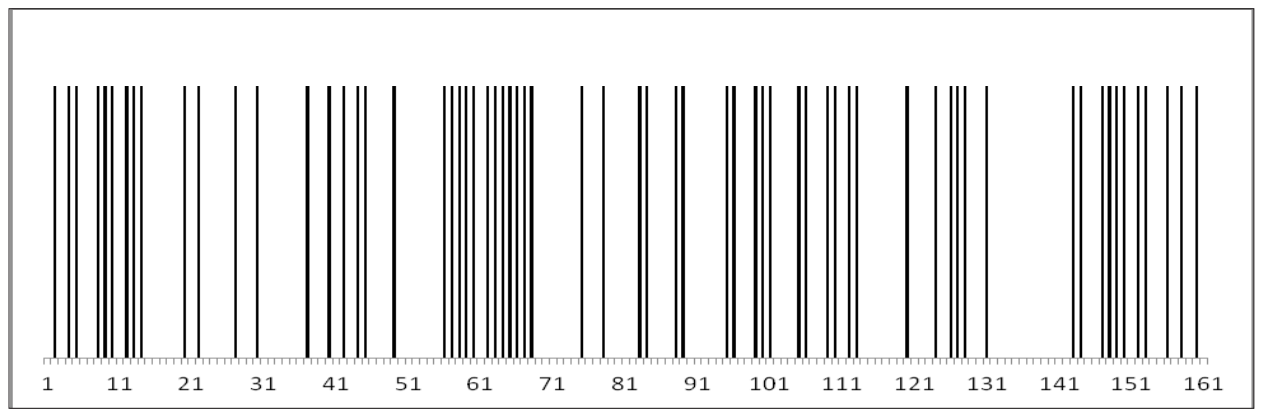

Figure 3. General aggression in "Gay societies are against the Angel campaign" (Delfi, October 4, 2006). 
Neutral comments follow largely the same patterns as the previous category of general aggressiveness (Figure 4). Although a motivation to develop a coherent discussion is not prevailing, people keep coming back to the point they would like to make concerning the topic under discussion, with statements like the following:

I cannot see anything deplorable in Angel's campaign. The criticism of gay societies aims to disguise the critics' dogmas as absolute truth. The right to have an opinion does not mean that everyone should think the same way. I suggest that all homophobic parents go and educate themselves a bit instead of crowing here in Delfi, and then they could raise their children as tolerant citizens.

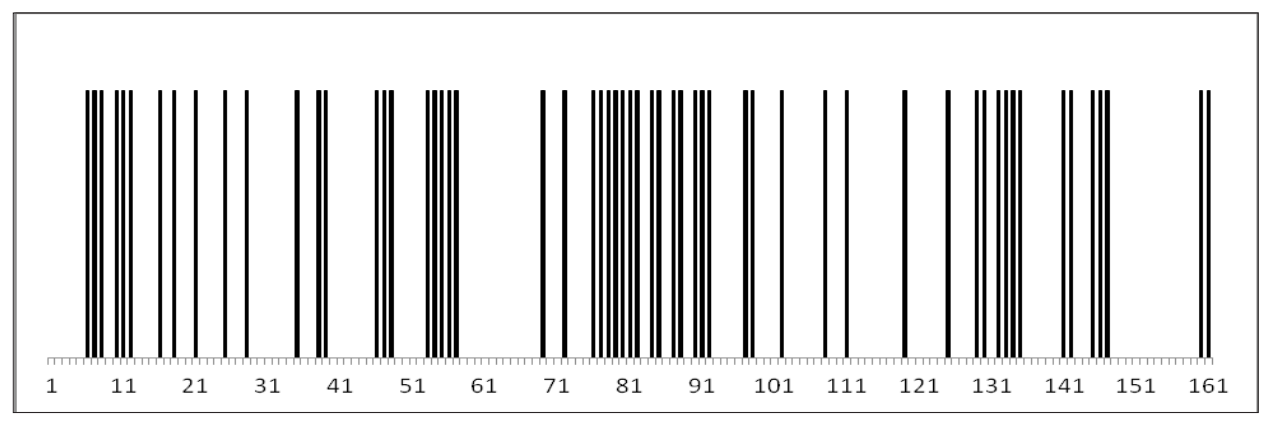

Figure 4. Neutral comments in "Gay societies are against the Angel campaign" (Delfi, October 4, 2006).

In all sequences that we have shown here, the tagged categories alternate according to a quite unified pattern. To generalise across the material, the sequences start out with humorous or neutral comments: the commentators may refer to the title of the news, distort it in a funny way, present stereotypes about the people or group whom the news concerns, etc. This is usually followed by a neutral discussion where different parties present their points of view; simultaneously, general aggression may be seen (e.g. angry statements about the government in general or a too tolerant society as a whole), but targeted aggression is not present. In the final section of the sequences, the discussion takes a more aggressive turn, and commentators start to verbally attack each other. Sometimes (but not in the cases above), if the motivation of the participants or their fascination with the subject is low, the comments in the ending section may also just 'fade away', in which case targeted aggression is not so visibly present there. 
In a very clear-cut manner, we see another interesting tendency in the material; namely, general aggression and a neutral mode of commenting spreads evenly across the threads. The density of both is rather even in the beginning, middle and end section. There can be a slight overlap in the modes, but more generally, when neutral discussion prevails (e.g. Figure 4, comments 51-55 and 75-90), there is less aggressiveness, and vice versa. At the same time, the second mutually complimentary pair - humour and targeted aggression - excludes each other, as we can see from Figures 1 and 2. This implies that targeted aggression towards fellow commentators is almost always humourless. To take this point further, the finding seems to echo several studies, although more theoretical in nature, which stress the mirthfulness of humour. We can say that some forms of humour can serve aggressive intent, but only to a certain degree. There is a point starting from which humour is not suitable or powerful enough to express anger or distress (see also Davies 2002). However, humour can turn into aggressiveness, which in turn can canalise into humour, as we see from the material for the present study: they do not happen simultaneously but alternate between one and the other. This result challenges approaches (most particularly, Gruner 1997) that tie all humour with aggression, which, as they claim, is the basic underlying mechanism of humour. In the analysed material we can see a different tendency: when discussion gets heated and commentators start attacking each other because of their identity or beliefs, humour (including sarcasm and irony) disappears from their comments. This leads us to think that neither humour nor its 'sharper' subgenres are useful in real conflict, nor is it more practical to refrain from comparisons, metaphors, exaggerations and other more playful forms of speech, etc., when the aim is to express anger. Christie Davies (2002) has mentioned that ethnic humour may coincide with ethnic conflicts in a given society, but the jokes that are told cannot be interpreted as a way of expressing the underlying hostility. There are much more effective means for doing this than through humour.

\section{Effects of failed humour in comment sequences}

In order to identify the factors that induce the change from a jocular mode of conversation into an aggressive one (turning to the second research question: Is failed humour more likely to bring about aggressive and insulting statements in Internet comment sequences?), let us look more closely at two of the comment sequences analysed above to see what reactions follow instances of attempted but unrecognised humour. 
The material shows that the failure of humour may, but does not necessarily cause a particular rise in the level of aggressiveness. Failed humour can equally result either in increased aggression or indifference (especially when a more intriguing and heated discussion is under way). Below, examples of both of these reactions are presented, taken from the same threads mentioned at the beginning of this chapter (p. 36). In the first sequence of comments that targets the former Minister of Education, who was accused of fawning over the Russian government when talking about Mari minorities in Russia, humour (or, rather, irony) is met with extended discussion about one of the commentators:

Mmanson: Sneer, Zebra, you have shitloads of black humour, but nobody understands it:)))

Patser: Actually, Zebra is the jewel of this place.

Zebra: abu is an abu is an abu...

Mmanson: zebras are zebras are zebras... Hallelujah, Zebrafuckers:)))

Zebra to Mmanson: I don't even doubt that your IQ is high.

Mmanson: I know where you live!

Zebra: Then come visit me someday.

Mmanson: Ok, I'll come, even if I don't want to...

Zebra: Why not? Are you afraid? Don't be, abu. I don't eat children.

(Reps: Külalistele vaeseid ei näidata 2005)

This is continued with a prolonged sub-thread in the comment sequence, dealing with personal remarks on the account of the user Zebra. Although the line of insult' does not start from one particular misinterpreted statement (instead, it is initiated by the active - even though initially neutral - participation of a pro-Russian commentator, Zebra), it gets a good incentive after Zebra uses the humorous nickname for allegedly dim-witted locals, 'abu'. Obviously meant as humorous nonsense, it is received with growing anger, and is further fuelled by other unfathomable statements (in miscoded Cyrillic) by the user Zebra. This case is thus an example of failed humour that grows into an online quarrel, although a mild and teasing type of quarrel rather than a straightforwardly insulting one.

The second thread presents an example of a rather heated exchange of opinions, especially because of the presence of a pro-gay commentator who joins in the discussion with comments that are highly aggressive, as in the comment by Undu to nurk: "Next time I'll take a gun and kill all the homophobes, because who doesn't let others live, shouldn't be living himself." The thread also contains two jokes with a punch-line, but both of them go unnoticed, even if they do offer a poignant comment on the discussion, as in the post by Lihtsalt joke: 
In a little village in Pskov oblast, grandpa and grandchild are sitting on a bench and grandpa tells about his memories of the war:

- Then the Germans came into our village, lined all the men up and asked if we wanted to be shot dead or sodomised.

- And then, grandpa, what happened next?

- I was killed, my boy, I was killed.

(Homoühendused taunivad Angeli kampaaniat 2006)

This does not, unlike the sudden presence of pro- and anti-gay commentators, increase the aggressive tonality. Nevertheless, it is against the backdrop of the aggressive statements (especially statements of targeted aggression) that jokes and other forms of humour are bound to fail more often. This is to say, while failed humour in itself does not cause more aggression in online comment boards, the presence of (and rise in) aggression definitely causes humour to fail. There are usually no clues in the threads which would inform the participants of CMC about the (humorous) intention and nature of a statement. In the examples cited above, the derogatory, but at the same time playfully absurd nickname ('abu') is perceived as intruding into, if not insulting to, the community of rather xenophobic commentators. It seems that instead of being concerned about the correct reception of one's statements, commentators are actively engaged in a battle of wits where casualties are not important; it is the few 'hits' that count.

The results lend support to those studies that claim that humour is not a form of aggression: when humour is present, direct and targeted aggression does not occur, and vice versa. It does not, however, clarify all the relevant details of the interrelations of an overall aggressive background and humour within an anonymous message board.

The findings concerning the patterns of aggression alternating with humour can be discussed in the light of the theoretical framework of online aggression in general. Research states that aggression is an outcome of several coinciding aspects: motivation, inhibition and opportunities provided by specific online contexts; it is not only a by-product of the anonymous environment as a whole. This holds largely true for the material in question, where permissive anonymity is backed up by a motivation to aggress provided by the journalists and other commentators. Delfi presents a clear preference to motivate through publishing provoking news texts. We can see a tendency of more aggressive comments in the case of provokingly verbalised news or posts which are ten times more likely to induce harmful comments (see Laineste 2012). Delfi is also not keen on restraining the users from using aggressive statements. Users are not required to log in, even for commenting - this causes high levels of anonymity and allows people to go there and 'act out' quite purposefully. This is an outcome of a number of factors, of which the economical factor must be foregrounded. Advertisements 
are sold by the number of clicks, and people are attracted to visit the site, read the news, and, more importantly, the comments, from which they can expect a good shot of adrenalin. Not all visitors comment, but they implicitly favour the action, the 'blood and tears' that the commentators provide.

The present study also describes the conditions of CMC where a joke falls flat. This is frequent in online communication, where social and non-verbal cues are limited. Very little, if any, of the humour in comment sequences is framed through conventionalised openings. People involved in the interaction do not signal that they are about to use humour; instead, they keep coming up with more comments, with quite an obvious attempt to outwit each other. In Hay's (2001) terms, no additional clues for the recognition of humour are given; humour is vested in each individual statement (see also Baym 1995). The 'game' of making the wittiest remark in itself seems to reward Internet commentators, and they are always ready to become engaged in this battle. This may sometimes, depending on the subject and the (identity-based) opinions of the participating Internet-users, evoke aggressive responses. It seldom happens that commentators are helped along with regard to recognition, understanding or appreciation of humour; CMC and the Internet as an environment in general seems to be reluctant to spell out humour. Instead, commentators are engaged in the battle of wits in a rather individualistic and socially non-coherent manner. They do not, at least in the anonymous environment that we examined, signal others about their intentions to joke, nor are they willing to recognise a joke that has been made. All in all, this motivates the commentators to outplay each other in their wittiness, cleverness, and aggressiveness - all at the same time - in order to make themselves visible to and be appreciated by the audience. It can be said that Internet humour is an expression or display of individuality and personal wit, and less, at least in the material used for this study, an indication of closeness and solidarity (for a different viewpoint, see Baym 1995).

The lack of a paratelic state (Apter 1982) mentioned earlier is another possible reason for humour to fail in the first place. The anonymous online message board is void of an immediate, positive and supportive atmosphere, which under other circumstances would form the premises for successful humour. The anonymous commentators in Delfi rarely laugh together in an earnest way. Instead, background of the conversations is a constant general aggressiveness (see Figure 3). A little detail or misunderstanding may occasionally lead to directed aggressiveness. Although the disposition to save face and be polite (initially described by Brown \& Levinson 1987) would suggest that failed humour should be met with supportive actions by other participants in the interaction, this does not happen in CMC. Politeness and face-saving is necessary for fostering 
cooperation and showing good intentions, but Internet users are not motivated to display social sensitivity because of rather loose and digressive ties between them. On the contrary: the Internet may offer a way out of these social norms that we as a community must exercise on a daily basis.

The results of this study, even if they do take us a step forward in understanding why humour fails, are not very helpful in pinpointing the possible effects of failed humour in CMC or relating these to certain types of utterances and/ or humour, as this would require more in-depth study (e.g. interviews with the commentators). According to the examples discussed above, unrecognised or misinterpreted attempts at humour may result in either silence or an increased level of aggression. Specific reactions depend on the underlying emotions (the thread is full of generally aggressive statements), emotional and intellectual involvement of the participants (the topic of the discussion is so interesting that all attempts at misleading the discussion into absurdity are ignored), the humorous potential of the news text and the playfulness of the commentators, etc., to name just a few. Further research is in order, and should include more examples of the context of failed humour that result in either of the reported reactions. On the basis of the current material, we are able to state that engaging in a game of wits is frequent among Internet commentators, and (due to the specific features of the media) this kind of humour often fails, but unlike in face-to-face communication, the consequent failure is treated superficially both by the initiators and the recipients of humour. This is not a serious matter for the initiator - even if someone is insulted, or a heated discussion starts, the person who wrote the (humorous) statement might, on the contrary, take pride in the uproar that he or she caused. The recipients, on the other hand, can just ignore lame jokes and carry on with the discussion or choose a new thread that is of more interest.

\section{REFERENCES}

Apter, Michael J. 1982. The Experience of Motivation: The Theory of Psychological Reversals. London: Academic Press.

Baym, Nancy K. 1995. The Performance of Humour in Computer-Mediated Communication. Journal of Computer-Mediated Communication, Vol. 1, No. 2, http:// onlinelibrary.wiley.com/doi/10.1111/j.1083-6101.1995.tb00327.x/full, last accessed on March 28, 2013.

Bell, Nancy 2009. Impolite Responses to Failed Humor. In: Neal R. Norrick \& Delia Chiaro (eds.) 2009. Humor in Interaction. Amsterdam \& Philadelphia, PA: John Benjamins Publishing Company, pp. 143-163. 
Blank, Trevor J. 2009. Introduction. In: Trevor J. Blank (ed.) Folklore and the Internet. Vernacular Expression in a Digital World. Logan: Utah State University Press, pp. 1-20. http://digitalcommons.usu.edu/cgi/viewcontent.cgi?article=1034\&cont ext=usupress_pubs, last accessed on February 26, 2013.

Brown, Penelope \& Levinson, Stephen C. 1987. Politeness: Some Universals in Language Usage. Cambridge: Cambridge University Press.

Brzozowska, Dorota 2009. Polish Jokelore in the Period of Transition. In: Liisi Laineste \& Arvo Krikmann (eds). Permitted Humour: Socialist, Post-Socialist and NeverSocialist Humour. Tartu: ELM Scholarly Press, pp. 127-170.

Davies, Christie 2002. Mirth of Nations. New Brunswick: Transaction Publishers.

Ellis, Bill 2001. A Model for Collecting and Interpreting World Trade Center Disaster Jokes. New Directions in Folklore, Vol. 5, https://scholarworks.iu.edu/dspace/ bitstream/handle/2022/7195/NDiF_issue_5_article_1.pdf?sequence=1, last accessed on February 26, 2013.

Gruner, Charles R. 1997. The Game of Humor. New Brunswick: Transaction Publishers.

Hancock, Jeffrey T. 2004. Verbal Irony Use in Face-To-Face and Computer-Mediated Conversations. Journal of Language and Social Psychology, Vol. 23, No. 4, pp. 447-463, doi: 10.1177/0261927X04269587.

Hay, Jennifer 2001. The Pragmatics of Humor Support. Humor: International Journal of Humor Research, Vol. 14, No. 1, pp. 55-82, http://dx.doi.org/10.1515/humr.14.1.55.

Hine, Christine 2005. Virtual Methods: Issues in Social Research on the Internet. New York: Berg Publishers.

Homoühendused taunivad Angeli kampaaniat. [Gay Societies are Against the Angel Campaign.] Delfi news portal, October 4, 2006; http://www.delfi.ee/news/paevauudised/eesti/homouhendused-taunivad-angeli-kampaaniat.d?id=14008951, last accessed on March 28, 2013.

Joinson, Adam N. 1998. Disinhibition and the Internet. In: Jayne Gackenbach (ed.) Psychology and the Internet: Intrapersonal, Interpersonal, and Transpersonal Implications. New York: Academic Press Inc., pp. 76-90.

Joinson, Adam N. 2007. Disinhibition and the Internet. In: Jayne Gackenbach (ed.) Psychology and the Internet: Intrapersonal, Interpersonal and Transpersonal Implications (2nd ed.). San Diego, CA: Elsevier Academic Press, pp. 76-92.

Justiitsministeerium 2007. Rassi- ja võõravimm Eestis. [Racism and Xenophobia in Estonia.] http://www.just.ee/orb.aw/class=file/action=preview/id=54339/Rassism +ja+ksenofoobia_18.05.2011.pdf, last accessed on March 28, 2013.

Kayany, Joseph M. 1998. Contexts of uninhibited online behavior: Flaming in social newsgroups on Usenet. Journal of the American Society for Information Science, Vol. 49, No.12, pp. 1135-1141, doi: 10.1002/(SICI)1097-4571(1998)49:12<1135::AIDASI8>3.0.CO;2-W.

Kiesler, Sara \& Zubrow, David \& Moses, Anne M. \& Geller, Valerie 1985. Affect in computer-mediated communication: An experiment in synchronous terminalto-terminal discussion. Human-Computer Interaction, Vol. 1, No. 1, pp. 77-104, doi:10.1207/s15327051hci0101_3. 
Kirschenblatt-Gimblett, Barbara 1996. The Electronic Vernacular. In: George E. Marcus (ed.) Connected: Engagements with Media. Chicago: University of Chicago Press, pp. 21-66.

Laineste, Liisi 2012. Verbal expressions of aggressiveness in Estonian Internet. In: Liisi Laineste \& Dorota Brzozowska \& Władysław Chłopicki (eds.) Estonia and Poland. Creativity and tradition in cultural communication. Tartu: ELM Scholarly Press, pp. 205-220, doi:10.7592/EP.1.laineste.liisi.

Lewis, Paul (ed.) 2008. The Mohammad Cartoons and Humour Research: A Collection of Essays. Humor: International Journal of Humor Research, Vol. 21, No. 1, pp. 1-46, doi:10.1515/HUMOR.2008.001.

Malamuth, Neil \& Linz, Daniel \&Yao, Mike 2009. The Internet and Aggression: Motivation, Disinhibitory and Opportunity Aspects. In: Yair Amichai-Hamburger (ed.) The Social Net: Human Behavior in Cyberspace. New York: Oxford University Press, pp. 163-191.

Martin, Rod 2010. What is Humor? Reversal Theory as an Integrating Framework. 10th International Summer School on Humour and Laughter: Theory, Research, Applications. Lecture materials, pp. 11-19.

Millard, William B. 1997. I Flamed Freud: A Case Study in Teletextual Incendiarism. In: David Porter (ed.) Internet Culture. New York: Routledge, pp. 145-159.

Norrick, Neal R. 1993. Conversational Joking: Humor in Everyday Talk. Bloomington: Indiana University Press.

Norrick, Neal R. \& Chiaro, Delia (eds.) 2009. Humor in Interaction. Amsterdam \& Philadelphia, PA: John Benjamins.

Reps: Külalistele vaeseid ei näidata. [Reps: They don't show the poor to the visitors.] Delfi news portal, August 17, 2005; http://www.delfi.ee/news/paevauudised/eesti/ reps-kulalistele-vaeseid-ei-naidata.d?id=10993273\&com=1\&s=1\&no=120, last accessed on March 28, 2013.

Oring, Elliott 2003. Engaging Humor. Urbana \& Chicago: University of Illinois Press. Priego-Valverde, Beatrice 2009. Failed Humor in Conversation: A Double Voicing Analysis. In: Neal R. Norrick \& Delia Chiaro (eds.) Humor in Interaction. Amsterdam \& Philadelphia, PA: John Benjamins, pp. 165-184.

Raskin, Victor 1985. Semantic Mechanisms of Humor. Dordrecht \& Boston \& Lancaster: Reidel.

Shmelev, Alexey \& Shmeleva, Elena 2009. Contemporary Russian Jokes: New Cast of Characters. In: Arvo Krikmann \& Liisi Laineste (eds.) Permitted Laughter. Socialist, Post-Socialist and Never-Socialist Humour. Tartu: ELM Scholarly Press, pp. 225-236.

Terezskiewicz, Anna 2012. Do Poles Flame? Aggressiveness in Polish Discussion Groups and Social Networking Sites. In: Liisi Laineste \& Dorota Brzozowska \& Władysław Chłopicki (eds.) Estonia and Poland. Creativity and Tradition in Cultural Communication. Tartu: ELM Scholarly Press, pp. 221-236, doi:10.7592/ EP.1.tereszkiewicz. 
Tsfati, Yariv \& Weiman, Gabriel 2002. www.terrorism.com: Terror on the Internet. Studies in Conflict \& Terrorism, Vol. 25, No. 5, pp. 317-332, http://dx.doi. org/10.1080/10576100290101214.

Zillmann, Dolf \& Cantor, Joanne R. 1976. A Disposition Theory of Humour and Mirth. In: Anthony J. Chapman \& Hugh C. Foot (eds.) Humour and Laughter: Theory, Research and Applications. London: Wiley, pp. 93-115. 